\title{
THYROID ASSOCIATED ORBITOPATHY - UNILATERAL PRESENTATION
}

\author{
H. R. Padmini, Madan Raj. M
}

1. Professor \& HOD. Department of Ophthalmology, Adichunchanagiri Institute of Medical Sciences.

2. Post Graduate. Department of Ophthalmology, Adichunchanagiri Institute of Medical Sciences.

\section{CORRESPONDING AUTHOR:}

Dr. H.R. Padmini

Adichunchanagiri Institute of Medical Sciences,

Mandya, Karnataka.

E-mail: prachi.subhedar@gmail.com

ABSTRACT: Thyroid-associated orbitopathy (TA0), frequently termed Graves ophthalmopathy, is part of an autoimmune process that can affect the orbital and periorbital tissue, the thyroid gland, and, rarely, the pretibial skin or digits (thyroid acropachy), Although the use of the term thyroid ophthalmopathy is pervasive, the disease process is actually an orbitopathy in which the orbital and periocular soft tissues are primarily affected with secondary effects on the eye. Thyroid orbitopathy (TO) is most prevalent among females in the fourth and fifth decades and is usually associated with thyroid dysfunction. Thyroid-associated orbitopathy may precede, coincide, or follow the systemic complications of dysthyroidism. The ocular manifestations of thyroid-associated orbitopathy include eyelid retraction, proptosis, chemosis, periorbital edema, and altered ocular motility with significant functional, social, and cosmetic consequences. we describe a unique case of unilateral exophthalmos in a young male patient.

REPORT OF A CASE: A 30 year old male patient presented with unilateral axial proptosis left eye for 6 months with eye signs of thyroid disease and history of diplopia on up gaze, increased appetite, weight loss, excessive sweating. He also gave complaints of red, gritty, photophobic and watery eyes. His visual acuity was in the right eye 20/40 improving to 20/20 and in the left eye it was 20/40 improving to 20/20. Color vision was normal. There was no RAPD present, Eye signs included Von Graffe's sign (immobility or lagging of the upper eyelid on downward rotation of the eye), Stellwag's sign (infrequent or incomplete blinking), Dalrymple sign (widened palpebral fissure), Gifford sign (Difficulty everting the upper eyelids), Pochin's sign (blinking rate is reduced), Rosenbach's sign (unusual tremor of the eyelids), Snellen's sign (Bruit heard on auscultation over the eye), Mean's sign (increased superior scleral show on upgaze), Kocher's sign (staring and frightened appearance), Möbius' sign (inability to maintain convergence of the eyes), Suker's sign (fixation becomes difficult in extreme lateral gaze). The intraocular pressure in the RE was $17 \mathrm{~mm} \mathrm{Hg}$ and LE was $19 \mathrm{~mm}$ of Hg. There was restriction of movements in the upgaze in the left eye. There was no corneal involvement. The visual fields were normal. Serum T3, T4 were normal with elevated TSH levels, B-scan showed thickened muscle belly of inferior rectus muscle. On CT scan Proptosis of the left eye noted (the distance from the interzygomatic line to anterior aspect of globe is $28 \mathrm{~mm}$ ), Increase in both intra and extraconal fat is noted in the left eye , Increase in the size and altered signal intensity is noted in the muscle belly of inferior rectus of left eye with sparing of the tendon. On histologic examination Fibrosis with degenerative changes in the eye muscles, Lymphocytic cell infiltration, Accumulation of mucopolysaccharides, interstitial edema with increased collagen production was seen. The patient was treated conservatively with maintenance of euthyroid 
state, as a supportive therapy, lubricant eye ointment at bedtime and an artificial tear during the day was given.

\section{Differential diagnosis includes:}

- Orbital and preseptal cellulitis, the onset of proptosis is often quicker, and the patient has other evidence of infection (e.g. fever, leukocytosis). On neuroimaging, the paranasal sinuses often are opacified.

- Carotid cavernous fistula, the patient may have a cranial bruit, and the dilated episcleral vessels extend to the limbus.

- Orbital inflammatory syndrome (orbital pseudotumor), often more painful, and progresses faster; the tendons are involved in orbital myositis, more often with ptosis than lid retraction.

- Other causes of thickened muscles include sarcoidosis, metastases, lymphoma, amyloid, and acromegaly.

- Dorsal midbrain syndrome (Parinaud syndrome) the globes elevate on the doll's head maneuver and the eye tends not to be injected or proptotic.

COMMENT: Most patients with thyroid-associated orbitopathy (TAO) can be observed, Monitor for visual loss from corneal exposure and optic neuropathy and for strabismus development, it is not recommended the use of eye exercises for patients with severe restrictive strabismus; doing so may elevate intraocular pressure. Visual field and color vision testing may help in early detection of visual loss. In patients with diplopia, prisms may be beneficial to those with smallangle and relatively comitant deviations. If a patient has dry eye symptoms, use of artificial tears during the day, lubricating ointment at night, and punctal plugs is considered, Tape occlusion of one lens or segment of the glasses may be helpful. If this does not work, try an occluder or vaulted eye patch

Systemic steroids are usually reserved for patients with severe inflammation or compressive optic neuropathy, Pulse intravenous steroids (eg, methylprednisolone $1 \mathrm{~g}$ every other day for 3-6 cycles) can be considered but may only marginally improve long-term disease outcome. If no response occurs after 48 hours, steroids probably will not work; at this point, the patient should have surgical decompression and maintain steroids. If a good steroid response occurs, orbital radiation may be considered. In severe cases of thyroid-associated orbitopathy, combined steroids, radiation, and surgery may be required. In patients with worsening TAO despite orbital decompression, intranasal steroids can be used. Adjunctive cyclosporine, octreotide, and intravenous immunoglobulin (IVIg) are less common modalities of medical treatment for optic nerve compression.

Orbital irradiation is sometimes is prescribed for moderate to severe inflammatory symptoms, diplopia, and visual loss in patients with thyroid-associated orbitopathy (TAO). The radiation (1500-2000 cGy fractionated over $10 \mathrm{~d}$ ) is usually administered via lateral fields with posterior angulation. Radiation is believed to damage orbital fibroblasts or perhaps lymphocytes, Radiation may be more effective if combined with steroid treatment, To prevent progression of thyroid-associated orbitopathy (TAO) from radioactive iodine, pretreating and post treating the patient with low-dose steroids (eg, $0.5 \mathrm{mg} / \mathrm{kg} / \mathrm{d}$ up to 2 months posttreatment) has been suggested. 
Surgery is usually performed during the quiescent cicatricial phase of the disease; the sequence of surgery is in the following order: 1) Orbital decompression 2) Strabismus surgery 3) Lid-lengthening surgery 4) Blepharoplasty

Orbital decompression can be performed in conjunction with an otorhinolaryngologist,

Patients with thyroid-associated orbitopathy (TAO) benefit from consultation and follow-up care with an endocrinologist. The clinician should be aware that thyroid-associated orbitopathy (TAO) can be asymmetric. In addition, optic nerve compression in thyroidassociated orbitopathy can occur in the absence of obvious proptosis; for this reason, always check for retropulsion.

\section{REFERENCES:}

1. Khalid BAK, Ng ML (1991) Thyroid eye disease - medical or surgical therapy. Ann. Acad. Med. Singapore 20: 273-276.

2. Denniston A, Dodson P, Reuser T (2002) Diagnosis and management of thyroid eye disease. Hospital Medicine 63: 152-156.

3. Scott IU, Siatkowski RM (1999) Thyroid eye disease. Seminars in Ophthalmology 14: 52-61.

4. Wiersinga WM (1998) Preventing Graves' ophthalmopathy [editorial]. N. Eng. J. Med. 338: 121-122.

5. Bartley GB (1994) Epidemiologic characteristics and clinical course of ophthalmopathy associated with autoimmune thyroid disease in Olmstead County, Minnesota. Trans. Am. Ophthalmol. Soc. 92: 477-588.

6. Char DH (1996) Thyroid eye disease. Br. J. Ophthalmol. 80: 922-926.

7. Feman SS (1994) Diabetes and thyroid-related eye disease. Curr. Opin. Ophthalmol. 5: 65-71.

8. Wiersinga WM, Prummel MF (2000) An evidence-based approach to the treatment of Graves' ophthalmopathyEndocrinol. Metab. Clin. North Am. 29: 297-319.

9. Solberg Y, Rosner M, Belkin M (1998) The association between cigarette smoking and ocular disease. Surv. Ophthalmol. 42: 535-547.

10. Bartalena L, Marcocci C, Bogazzi F et al (1998) Relation between therapy for hyperthyroidism and the course of Graves' ophthalmopathy. N. Eng. J. Med. 338: 7378.

11. Tallstedt L, Lundell G, Toorring O, Wallin G, Ljunggren JG, Blomgren H et al (1992) Occurrence of ophthalmopathy after treatment for Graves' hyperthyroidism. N. Eng. J. Med. 326: 1733-1738.

12. Marcocci C, Tanda ML, Manetti L et al (1999) Intravenous and oral glucocorticoid therapy in patients with severe Graves' ophthalmopathy: Results of a randomized, single-blind, prospective study. J. Endocrine Invest. 22 (suppl 6):104.

13. Mourits MP, Kampen van-Harteveld L, Garcia MB, Koppeschaar HP, Tick L, Tarwee CB (2000) Radiotherapy for Graves' orbitopathy: randomized placebo-controlled study. Lancet 29; 355: 1505-1509.

14. Miller ML, Goldberg SH, Bullock JD (1991) Radiation retinopathy after standard radiotherapy for thyroidrelated ophthalmopathy [letter]. Am. J. Ophthalmol. 112: 600-601.

15. Bartalena L, Pinchera A, Marcocci C (2000) Management of Graves' ophthalmopathy: reality and perspectives. Endocrinol. Rev. 21: 168-199. 
16. Bartley GB, Gorman CA (2002) Perspective - Part 1: then Mayo orbital radiotherapy for Graves' ophthalmopathy (ORGO) study: lessons learnt. Ophthal. Plast. Reconstr. Surg. 18: 170-172.

17. Kung AWC, Michon J, Tai KS, Chan FL (1996) The effect of somatostatin versus corticosteroid in the treatment of Graves' ophthalmopathy. Thyroid 6: 381-384.
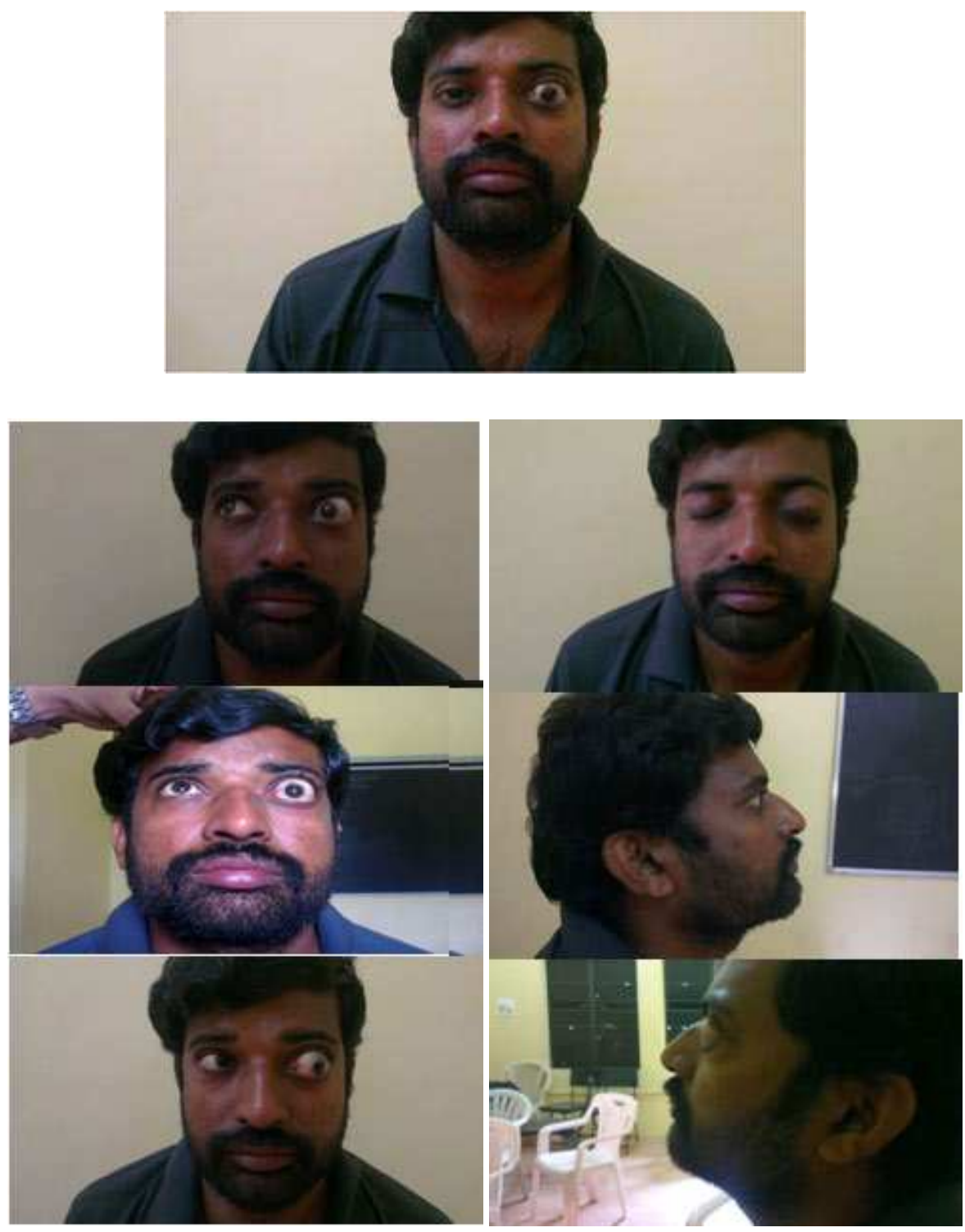
CASE REPORT
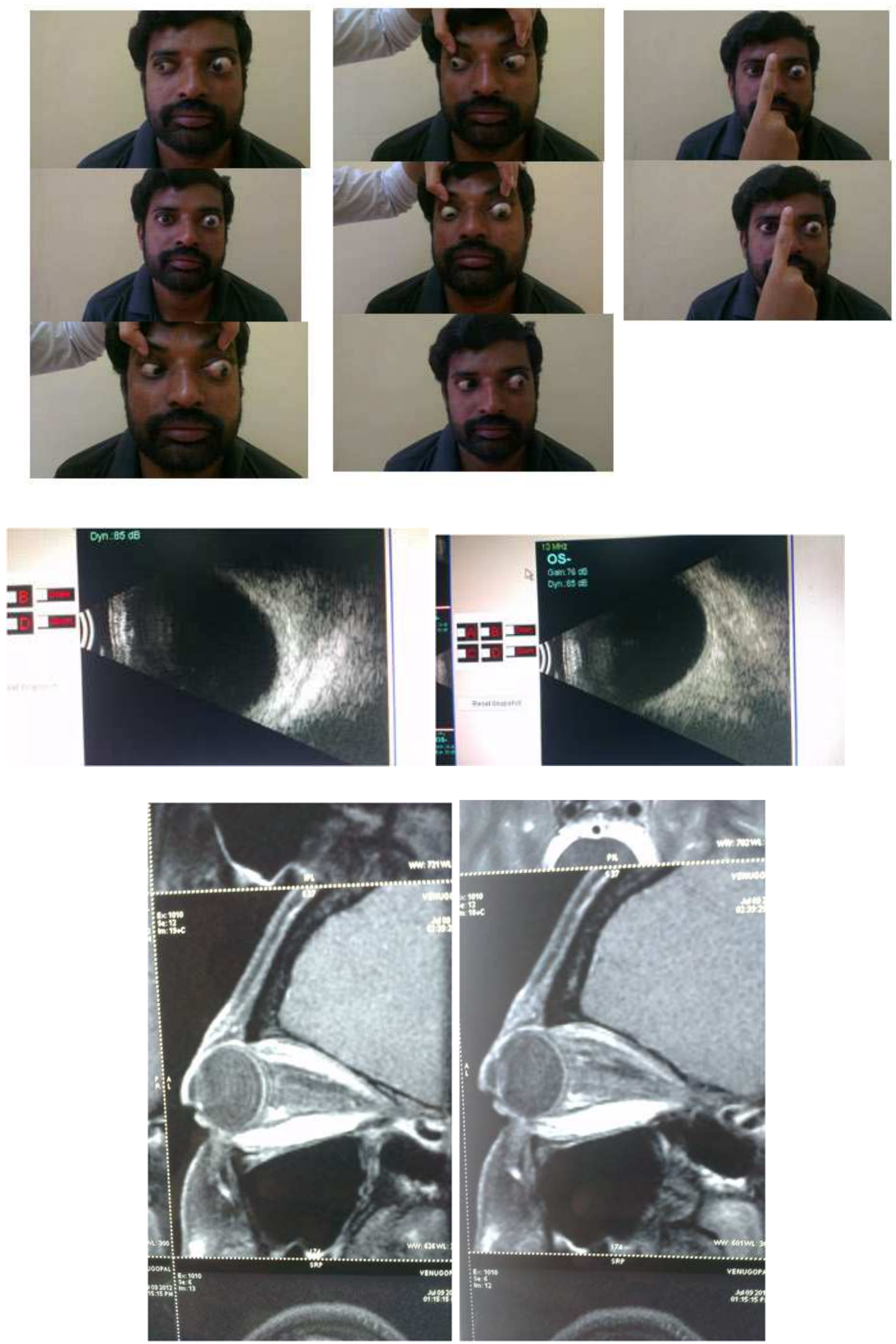
CASE REPORT
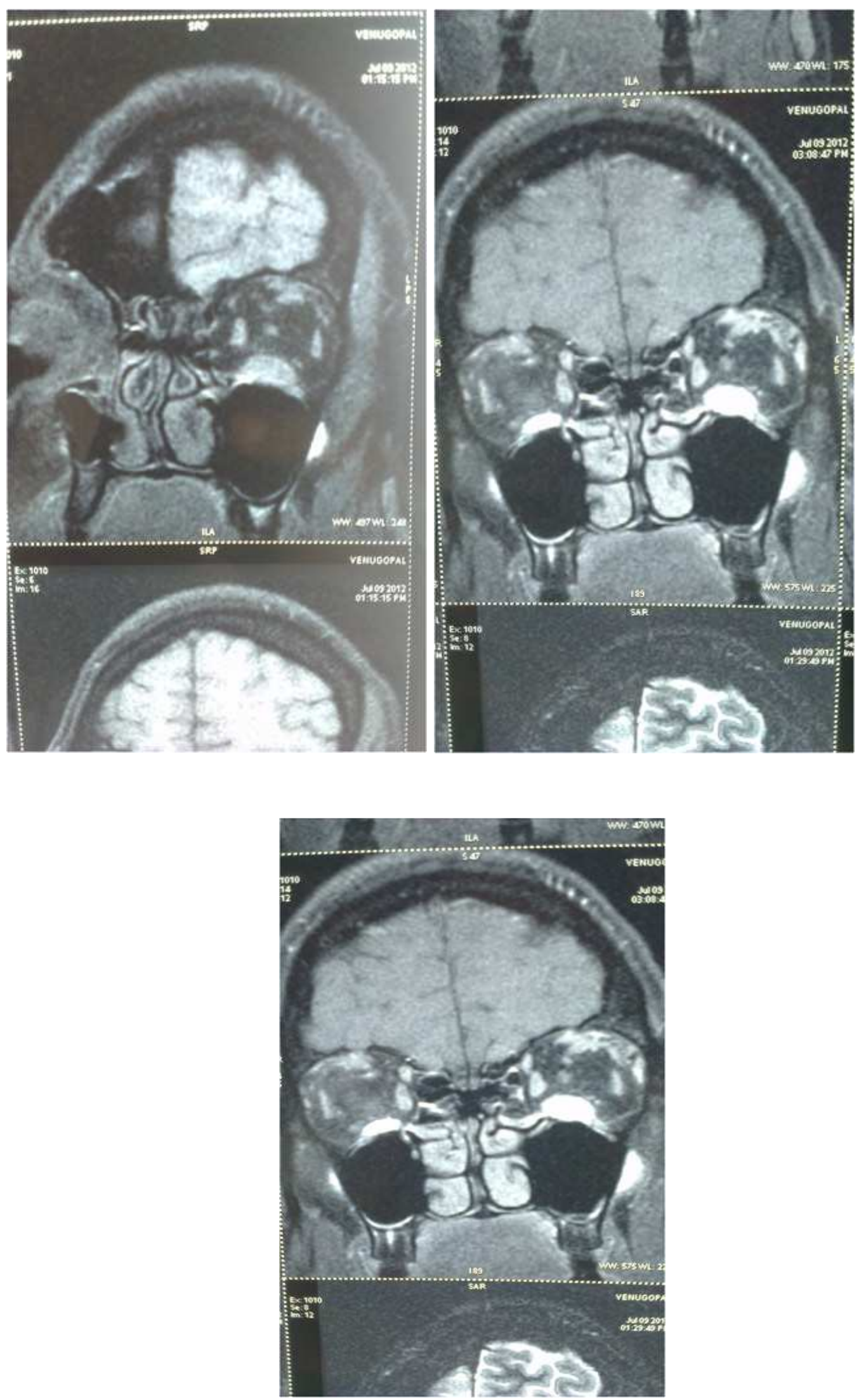